\title{
AVALIAÇÃO GEOESTRUTURAL E CARACTERIZAÇÃO TECNOLÓGICA DO SIENITO MARROM IMPERIAL LOCALIZADO NO MUNICÍPIO DE JOÃO ALFREDO-PE
}

\author{
Maria Carolina de Albuquerque Feitosa Amador ${ }^{1}$ \\ Márcio Luiz de Siqueira Campos Barros ${ }^{2}$ \\ Vanildo de Almeida Mendes ${ }^{3}$ \\ 10.18190/1980-8208/estudosgeologicos.v29n2p63-78 \\ ${ }^{1}$ Instituto Federal de Educação, Ciência e Tecnologia do Rio Grande do Norte, \\ maria.feitosa@ifrn.edu.br \\ ${ }^{2}$ Universidade Federal de Pernambuco, mlbarros@ufpe.br \\ ${ }^{3}$ CPRM Serviço Geológico do Brasil, vanildo.mendes@ cprm.gov.br
}

\section{RESUMO}

Através de avaliações das fraturas de um maciço rochoso é possível compreender as forças agentes dos movimentos que provocaram as suas descontinuidades. Tal entendimento é fundamental para o controle das mesmas, o que resulta numa lavra de rochas ornamentais mais eficiente e de maior aproveitamento mineral, haja vista que as dimensões e qualidade dos blocos obtidos dependem principalmente da natureza e equidistância dos fraturamentos controlados pela distribuição das tensões atuantes, dessa forma reduz-se os passivos ambientais tão comuns neste tipo de extração. Neste trabalho, apresenta-se a análise estrutural do Sienito Marrom Imperial, localizado no distrito de Umari, zona rural do Município de João Alfredo-PE. Os dados coletados durante a visita técnica constituíram um banco de dados utilizado na construção de projeções estereográficas e diagramas de rosetas. Com base nos resultados pode-se concluir que a direção SE-NW é a melhor orientação de corte, para o desenvolvimento dos trabalhos de abertura da pedreira, de modo a provocar o alívio das tensões e evitar o desenvolvimento de fraturas durante os serviços de lavra. Quanto à caracterização tecnológica, os resultados obtidos foram comparados aos estabelecidos pelas normas ABNT NBR 15845:2010, NBR 12042:1992 e ASTM C 615:1992. Os índices físicos e ensaio de desgaste Amsler atenderam satisfatoriamente às referidas normas. Os dados dos ensaios de resistência à compressão simples e resistência à flexão mostram que a rocha suporta uma compressão mediana, levemente inferior ao estabelecido pelas já referidas normas. Com base nos resultados e análise petrográfica, a rocha não pode ser aplicada em locais úmidos e de intenso tráfego, devido ao seu grau de absorção de água e resistência à compressão simples abaixo dos limites estabelecido pela norma ASTM C615 e ABNT NBR 15845.

Palavras chave: Marrom Imperial. Geologia estrutural. Tensão. Rocha ornamental. Caracterização tecnológica.

\section{ABSTRACT}

Through evaluating the fractures of rocky mass makes it possible to understand the forces that caused movements that generate their discontinuities. Such understanding is fundamental to control them, which results in a more efficient ornamental rock drilling and a better exploitation, since the dimensions and quality of the blocks obtained depend mainly on the nature and equidistance of fractures controlled by the distribution of the active voltages, resulting in the reduction of the environmental liabilities so common in this type of extraction. In this work, the structural analysis of the Imperial Brown Sienito is presented, 
located in the district of Umari, rural area of João Alfredo in Pernambuco- BRA. The data collected during the technical visit supplied a database used in the construction of stereographic projections and rosette diagrams. Based on the results, it can be concluded that the SE-NW direction is the best cutting orientation for the development of the opening the quarry work for tension relieving and development of fractures during mining services. For technological characterization, the results obtained in the work were compared to those established by ABNT NBR 15845: 2010, NBR 12042: 1992 and ASTM C 615: 1992 standards. The Amsler physical indexes and wear tests satisfactorily met those standards. The data of the tests of resistance to simple compression and resistance to flexion shows that the rock endures a medium compression, slightly inferior to the one established by the mentioned norms. According to the results and petrographic analysis, the rock can not be applied in humid places and intense traffic, due to its degree of water absorption and simple compressive strength below the limits established by ASTM C615 and ABNT NBR 15845.

Keywords: Brown Imperial. Structural geology. Tension. Ornamental Rock. Technological characterization.

\section{INTRODUÇÃO}

As rochas são genericamente definidas como corpos sólidos naturais, formados por agregados de um ou mais minerais. Devido à pluralidade de suas feições e notável beleza de seus padrões estéticos, associada a alta resistência e durabilidade, as rochas ornamentais e de revestimento vêm se consagrando na história. Seus principais campos de aplicação incluem tanto peças isoladas, como esculturas, tampos e pés de mesa, balcões, arte funerária em geral, sem omitir os revestimentos internos e externos de paredes, pisos, pilares, colunas, soleiras etc.

Apesar de ampla utilização, algumas práticas, a exemplo da determinação e orientação das tensões no maciço, ainda não são aplicadas pelas empresas de mineração, o que ocasiona muitas perdas durante o processo de extração. Segundo Vidal, Azevedo e Castro (2013), vários motivos concorrem para a falta de atenção à pesquisa geológica de detalhe por parte dos empresários; dentre estes podemos destacar: desconhecimento, falta de interesse em função de grandes reservas ou até mesmo o impulso em pular etapas visando antecipar o retorno financeiro.

No entanto, a falta de pesquisa geológica de detalhe tem conduzido à lavra predatória de matacões e maciços rochosos, gerando grande volume de rejeitos, como visto na figura 1 . Este problema reduzo percentual de lucratividade, implicando em perda de competitividade, podendo, em certos casos, culminar com o abandono das frentes de explotação. Tal fato, além do prejuízo econômico-financeiro e das frustrações causadas no investidor, ocasiona danos irreparáveis ao meio ambiente e desalento nascomunidades locais que na sua grande maioria veem na mineração uma oportunidade de crescimento econômico-social. 


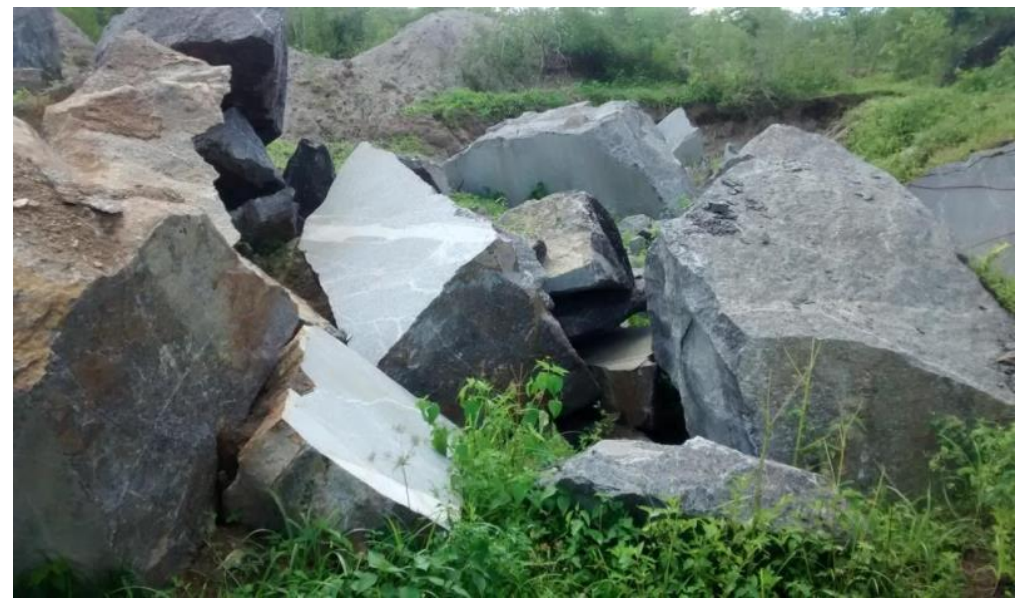

Figura 1. Rejeitos da lavra em Umari- João Alfredo -PE.

O objetivo principal deste trabalho é realizar análise geoestrutural de maciços rochosos para aplicação em rocha para fins ornamentais, considerando parâmetros de orientação espacial (atitudes) e assim nortear a explotação da rocha na zona de alívio do campo de tensões atuantes sobre o maciço rochoso.

Realizar a caracterização tecnológica da rocha, visando a determinação do melhor uso para a mesma. Esse estudo é uma vez que não é incomum surgirem problemas de inadequação do material para o uso pretendido. Vidal, Azevedo e Castro (2013), estabelecem que a determinação das propriedades das rochas deve ser realizada por meio de ensaios e análises normalizadoras, em laboratórios especializados, que tem por objetivo a obtenção dos parâmetros petrográficos, físicos e mecânicos, cuja análise permitirá a recomendação do uso mais adequado da rocha no revestimento de edificações, bem como subsidiarão a elaboração de projetos arquitetônicos.

\section{Tensões em maciços rochosos}

O estado de tensões da massa rochosa é espacialmente variável em função da presença de feições estruturais (tais como falhas; fraturas; foliação; lineação, etc) ou da variação local nas propriedades da rocha. $\mathrm{O}$ atual estado de tensões que atua em um determinado elemento da crosta terrestre deve levar em consideração não apenas as condições atuais de tensões, mas também, os esforços sofridos pelo corpo rochoso por todo histórico geológico. Portanto, o estado natural de tensão resulta de sucessivos eventos, ocorridos durante a história geológica do maciço rochoso, correspondendo ao produto de vários estados de tensões anteriores.

A tensão induzida procede da redistribuição das tensões preexistentes. É provocada pela perturbação do maciço com a implantação de obras de engenharia, como escavações ou construções, as quais são capazes de gerar tensões devido à retirada ou acúmulo de material, respectivamente, a exemplo do que acontece na extração de blocos de rochas ornamentais.

Considerando-se um corpo rochoso, funcionando como corpo de prova, numerosas fraturas são formadas após ação compressiva. Tais cisalhamentos aumentam em número e dimensões até que o corpo se rompa definitivamente (Fig. 2). Estes rompimentos ocorrem ao longo de fraturas longitudinais a direção principal 
de tensão ou através do desenvolvimento de superfícies de cisalhamento com ângulo teórico de $45^{\circ}$ com a direção de compressão máxima. Pelo exposto na referida figura, conclui- se que a direção de tensão máxima $\sigma 1$ constitui a bissetriz do ângulo que os planos de cisalhamento fazem entre si, o qual é menor que $90^{\circ}$ e em geral próximo a $60^{\circ}$, (Mendes, 2008).

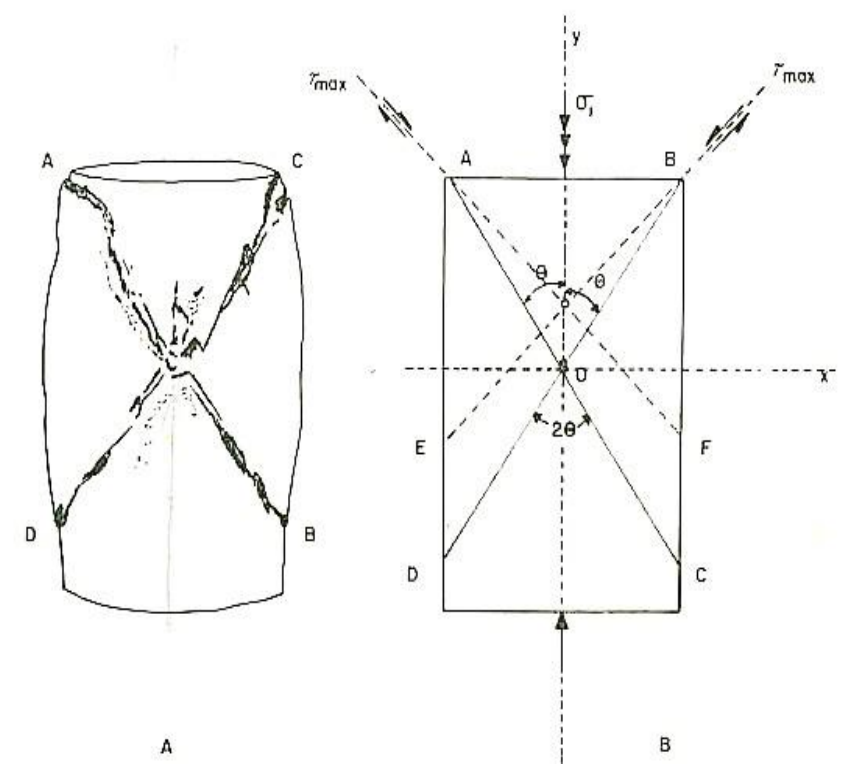

Figura 2. Desenvolvimento de fraturas de cisalhamento desenvolvidas sob ensaios de compressão. Fonte: Ladeira e Loczy (1976).

Ensaios de laboratório descritos em Ladeira e Loczy (1976) revelam que se um prisma submetido a uma carga compressiva estiver em meio fluido, que lhe exerça uma pressão hidrostática elevada, encerrada a compressão e retirando-se o prisma da máquina, observar-se-ão numerosas fraturas normais ao eixo de compressão. $\mathrm{O}$ mesmo acontece com o corpo rochoso em profundidade, quando sofre alívio de carga causado pela retirada do capeamento rochoso que a comprimia, o que provoca $o$ aparecimento de fraturas paralelas a superfície do relevo. As fraturas de acomodação ou alívio constituem fraturas de tensão geradas pela expansão do corpo rochoso, após se suprimir a atuação da tensão compressiva. Já as fraturas de extensão são resultantes da expansão das dimensões do bloco paralelas ao lado do prisma e da direção da compressão máxima, como observado na figura 3 .

Segundo Ragan (2009), para aprender como as rochas se comportam sob vários estados de tensão, é necessário realizar experimentos que reproduzam as condições naturais o mais próximo possível. No teste triaxial convencional, uma carga é aplicada às extremidades de um cilindro rochoso imerso em um fluido pressurizado. Nesta configuração, $\sigma 1$ é paralelo ao eixo do cilindro. As magnitudes das outras duas tensões principais são iguais à pressão no meio confinado e isso é comumente chamado de pressão confinante. Em baixas pressões de confinamento, a amostra de rocha é fraturada, se a fratura ocorrer antes da distorção permanente, o material é frágil; se uma pequena distorção permanente $(\leq 5 \%)$ precede a fratura, é semi-frágil. Em pressões confinantes mais altas, o modo deformacional é inteiramente dúctil. 

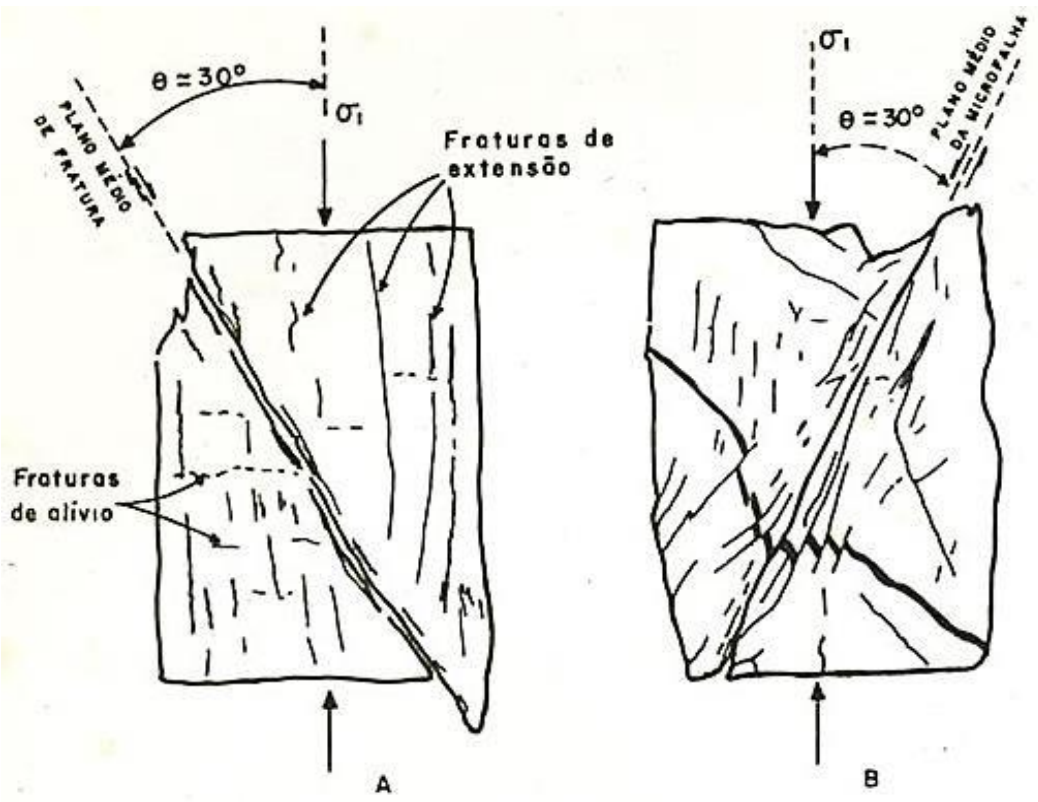

Figura 3. Desenvolvimento de fraturas de cisalhamento (inclinadas), de tensão (verticais) e as de alívio (horizontais), estabelecidas em espécimes rochosos submetidos à compressão. Fonte: Ladeira e Loczy (1976).

\section{Localização e geologia local}

A área em questão situa-se na região agreste do Estado de Pernambuco, próximo ao Sítio Pau Santo, distrito de Umari do município de João Alfredo, inserida na Folha Surubim SB.25-Y-CIV. No geral as vias de acesso são consideradas boas, permitindo o tráfego de veículos pesados o ano todo, a figura 4 apresenta o mapa de localização da área de estudo. O granito (1.s) estudado possui textura inequigranular, estrutura maciça e granulação fina a média. A região da pedreira faz parte de um extenso corpo plutônico com dimensões de um "batólito", o qual se encontra intrudido no Complexo Migmatítico-Granitóide. De modo resumido, o corpo é considerado um mela-sienito grosso, nos quais os megacristais de feldspato potássico e cor marrom escura dispõem-se em uma matriz rica em anfibólio, biotita e plagioclásio, além de auréolas de microclina rósea que circundam os megacristais de K-feldspato. Esta rocha constitui cumulatos inclusos em um quartzo sienito porfirítico pertencente a denominada Suíte shoshonítica de amplitude regional. A Suíte Shoshonítica é uma das unidades mais prospectivas do Neoproterozóico pernambucano.

Nos mela-sienitos os feldspatos aparecem sob a forma de cristais, variando de euedricos a subedricos, com bordas arredondadas. Contém microfraturas restritas aos limites dos grãos. Apresentam frequentemente um zoneamento muito nítido, com uma auréola de feldspato róseo (augita- esse mineral é um prioxênio) em torno dos grãos, como visto na figura 5. A figura 6 apresenta o mapa geológico da área de estudo. 


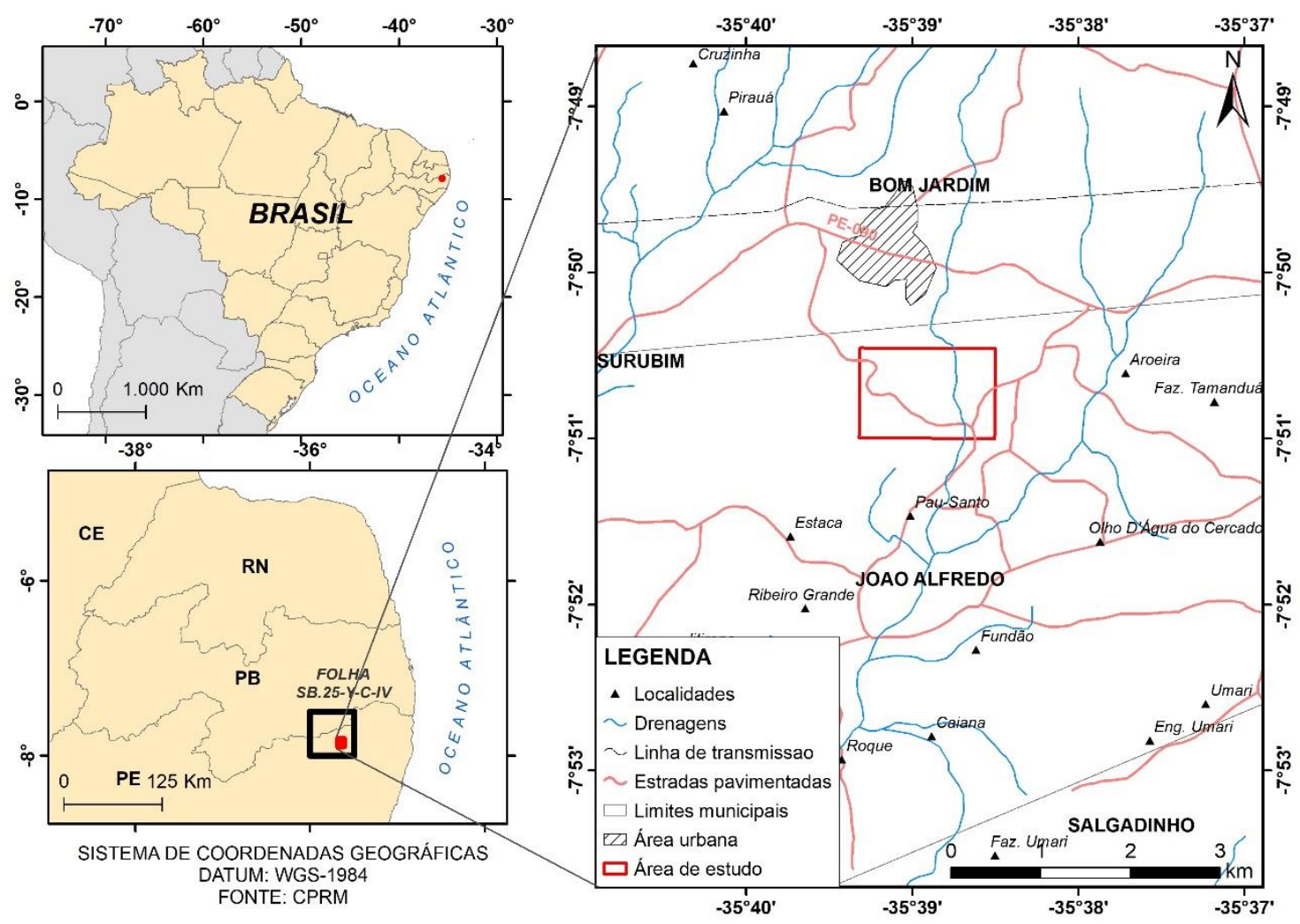

Figura 4: Mapa de localização da área estudada. Fonte: Autora.

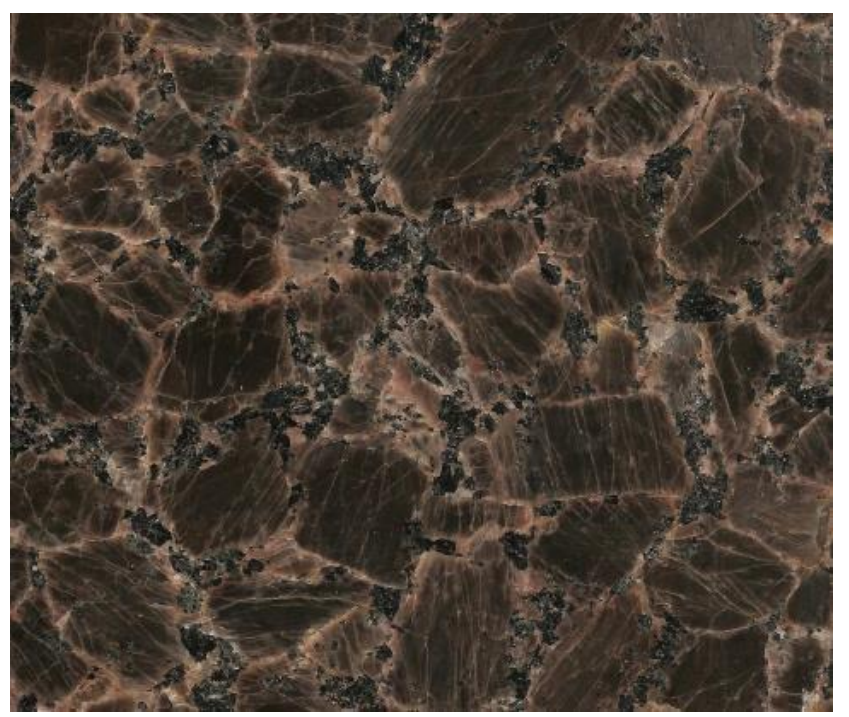

Figura 5. Foto de uma placa polida de Marrom Imperial. 


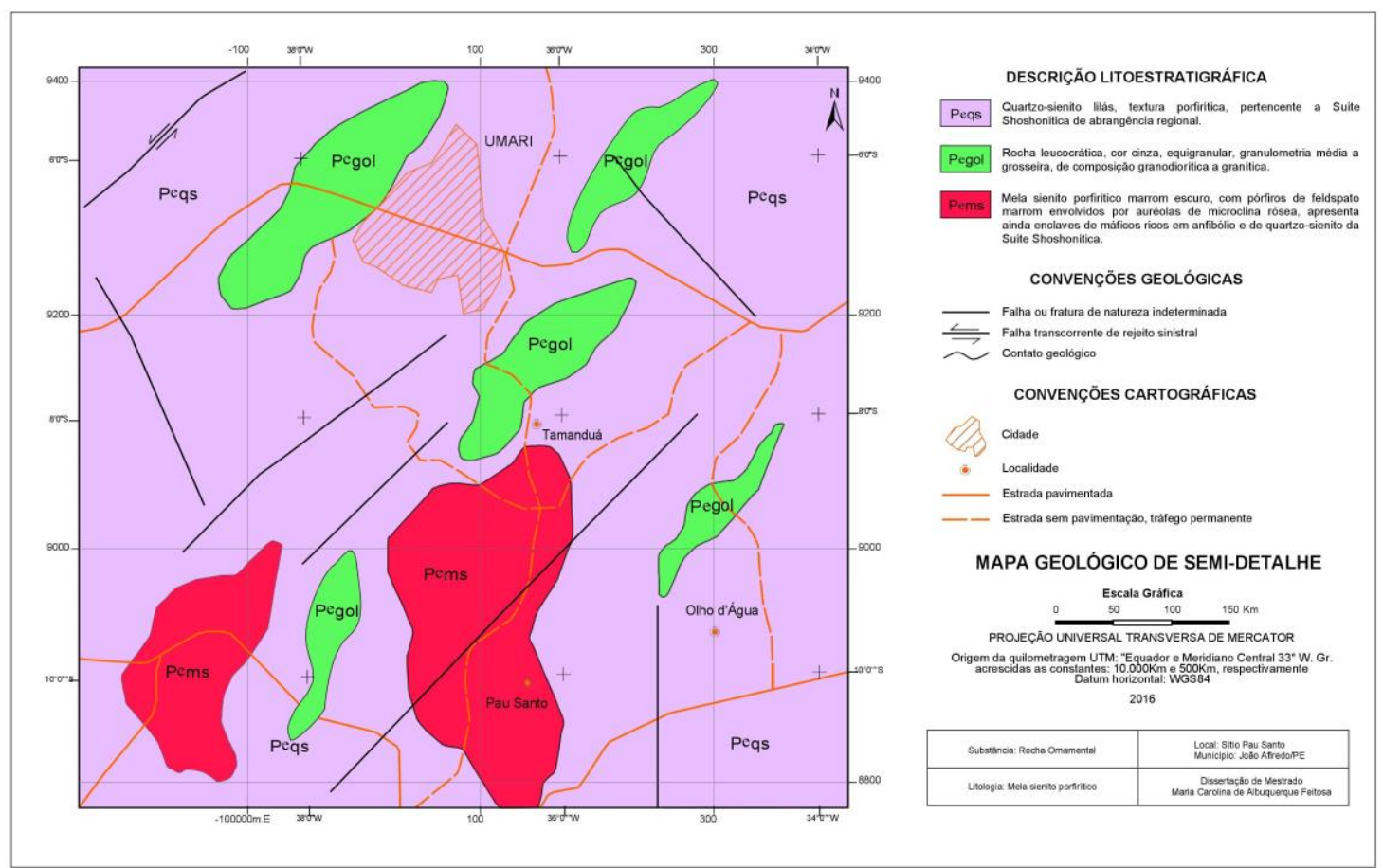

Figura 6. Recorte do mapa geológico da área de estudo. Fonte: Autora.

\section{Caracterização tecnológica}

Segundo Vidal, Azevedo e Castro (2013), as rochas ornamentais têm um valor comercial que resulta da demanda do mercado consumidor, especialmente por motivos ligados a suas propriedades de resistência, aptidão ao corte, polimento e beleza estética. Tal aspecto torna praticamente cada rocha única, tornando o estudo destes materiais e de suas propriedades um tema bastante complexo e particular, o que reforça a necessidade da caracterização tecnológica de cada rocha. As características físico-químicas que garantem a certas rochas tais tributos, resultam de sua gênese e composição mineralógica, associadas a sua história geológica; i.e. relação com os eventos geológicos da região (no caso o ciclo Brasiliano).

Na Tabela 1 são descritos os requisitos das características físicas e mecânicas para material granítico destinados a revestimentos verticais e horizontais de exteriores e de interiores de construções segundo às normas brasileira (NBR 15845:2010) e americana (ASTM C615:1992). 
Tabela 1. Valores especificados para granitos pela ABNT NBR 15845 E ASTM C615.

\begin{tabular}{|c|c|c|}
\hline Propriedades & ABNT NBR 15845 & ASTM C615 \\
\hline Densidade aparente $\left(\mathrm{Kg} / \mathrm{m}^{3}\right)$ & $>2.550$ & $\geq 2.560$ \\
\hline Porosidade aparente $(\%)$ & 1,0 & N.E \\
\hline Absorção d'água (\%) & $<0,4$ & $\leq 0,4$ \\
\hline Compressão uniaxial $(\mathrm{MPa})$ & $>100$ & $>131$ \\
\hline Módulo de ruptura em 3 ptos (MPa) & $>10,0$ & $>10,34$ \\
\hline Módulo de ruptura em 4 ptos (MPa) & $>8,0$ & $>8,27$ \\
\hline Coeficiente de dilatação térmica linear & $<8,0$ & N.E \\
\hline Impacto de corpo duro $(\mathrm{m})$ & $>0,3$ & N.E \\
\hline Desgaste Amsler $(\mathrm{mm} / 1000 \mathrm{~m})$ & $<1,0$ & N.E \\
\hline
\end{tabular}

A análise petrográfica é realizada através de exames macroscópicos de amostra in natura e microscópico de lâminas delgadas das rochas, com espessura de $30 \mu \mathrm{m}$ ao microscópio de luz transmitida; consiste na descrição dos minerais (arranjo textural), que permitem identificar a natureza ou tipo de rocha, os minerais presentes e suas inter-relações, $o$ grau de alteração, o estado microfissural dos cristais, sua granulação e textura, além de outras características que possam influenciar na durabilidade da rocha.

\section{RESULTADOS E DISCUSSÕES}

\section{Orientação das tensões no maciço estudado}

Observações de campo mostram que a área apresenta um par conjugado de fraturas de cisalhamento disposto em direção N30E e N40W. A bissetriz do ângulo formado pelo cruzamento destes cisalhamentos corresponde à direção de compressão máxima, ou seja, na direção N5E tem-se o eixo de maior esforço atuante sobre a área, como visto no diagrama de projeção estereográfica da figura 7. A interpretação destes diagramas, construídos com o uso do software Openstereo do Instituto de Geociências da USP, perpendicularmente ao eixo de compressão máxima disposta nas direções entre $30^{\circ} \mathrm{Az}$ e $340^{\circ} \mathrm{Az}$, temse a zona de alívio.

Uma forma de fácil de identificar o resultado do cisalhamento é através da análise das fraturas, pela sua face perfeitamente lisa, com minerais orientados e estirados de acordo com a direção de movimento da força. A partir das figuras 8 e 9 nota-se o baixo ângulo de rake, característico das fraturas de cisalhamento 


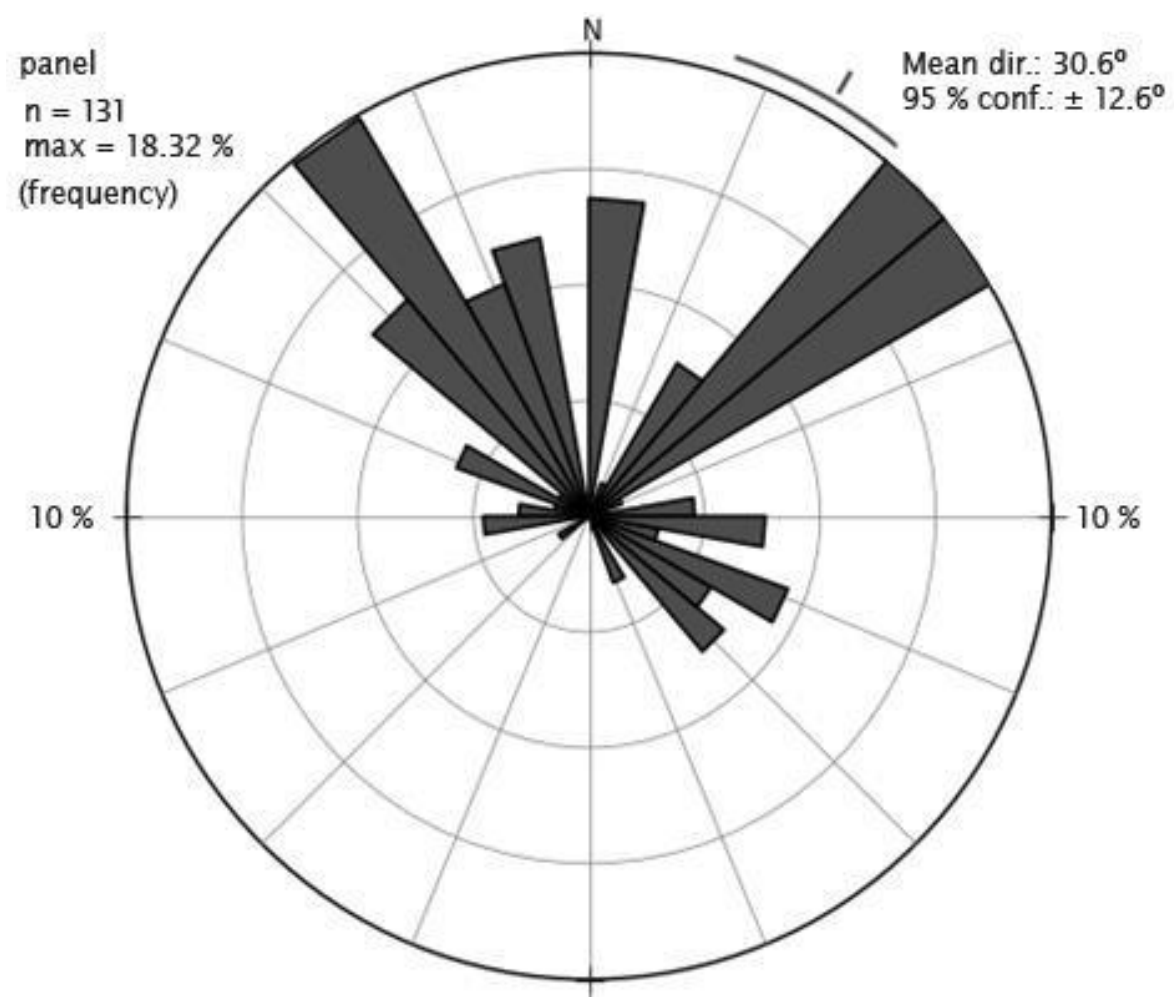

Figura 7. Diagrama de rosetas onde se visualiza um par conjugado de cisalhamento nas direções $30^{\circ} \mathrm{Az}$ e $340^{\circ} \mathrm{Az}$.

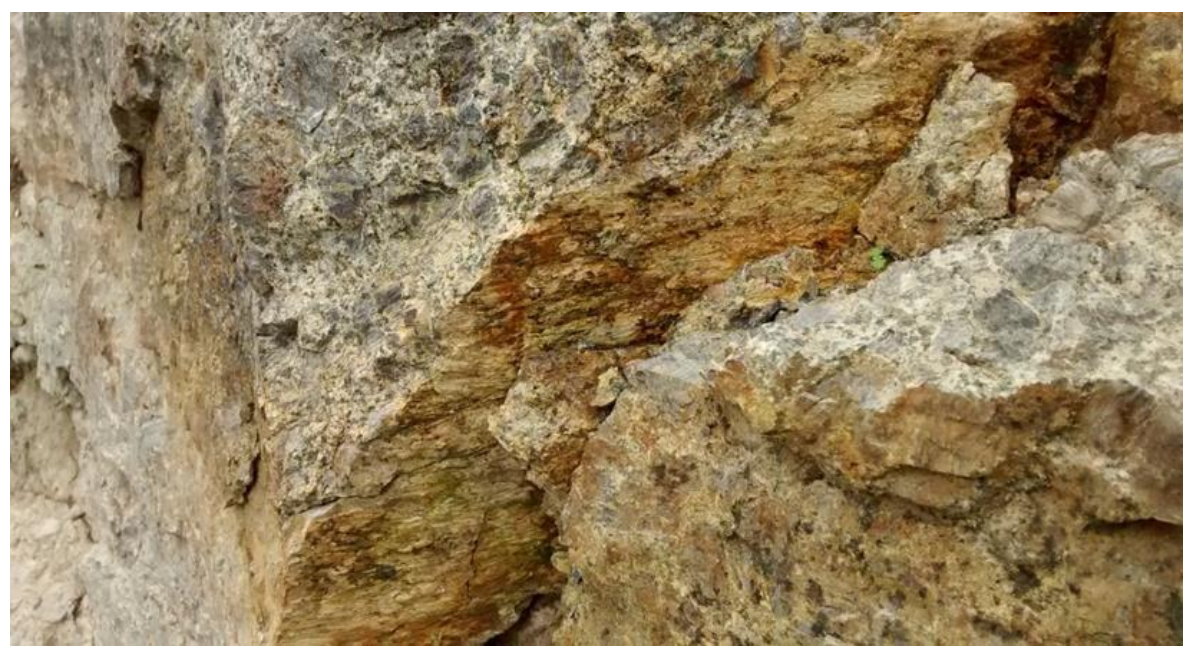

Figura 8. Minerais orientados segundo uma lineação de estiramento lx no plano. 


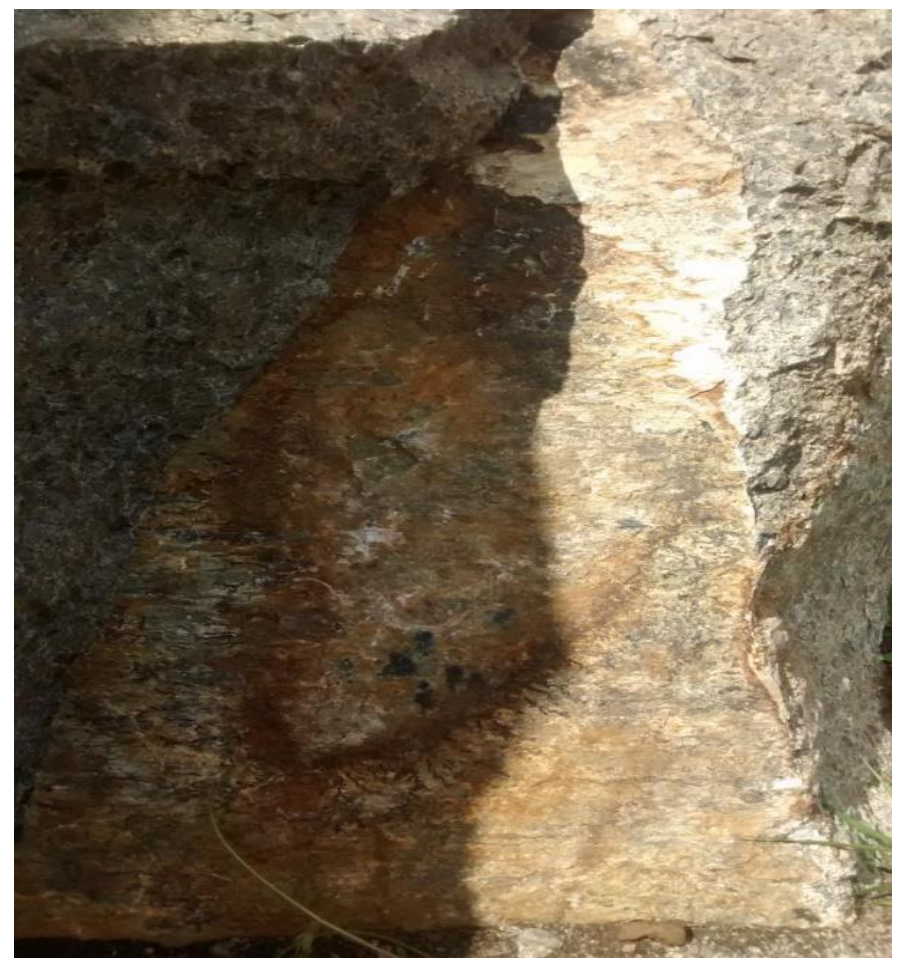

Figura 9. Face mostrando a superfície de cisalhamento.

A figura 10 mostra um par de fraturas cisalhantes na área de pesquisa. A figura 11 exibe a fratura de alívio. Notamse semelhanças encontradas no livro de
Ladeira e Loczy (1976) que mostra o desenvolvimento de fraturas de cisalhamento desenvolvidas sob ensaios de compressão e de alívio

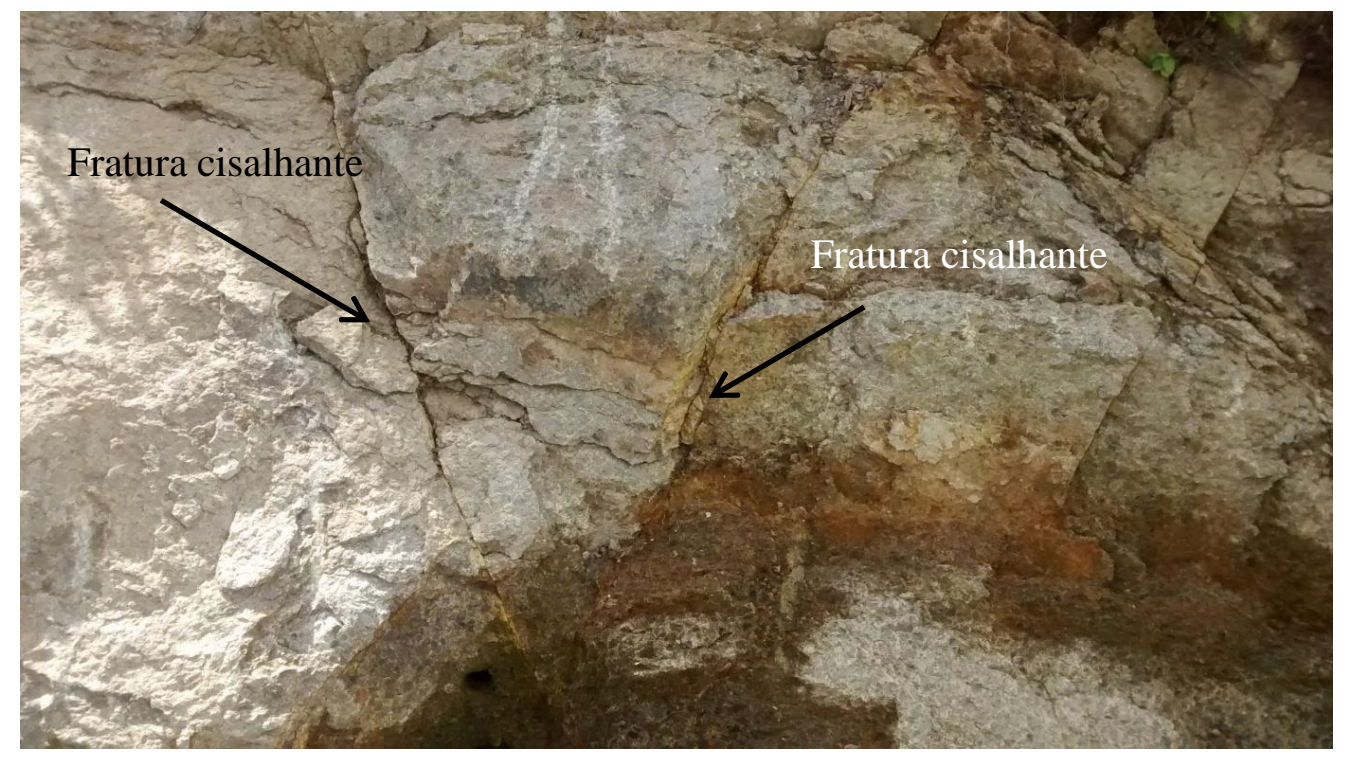

Figura 10. Fratura de cisalhamento em Umari, João Alfredo-PE. 


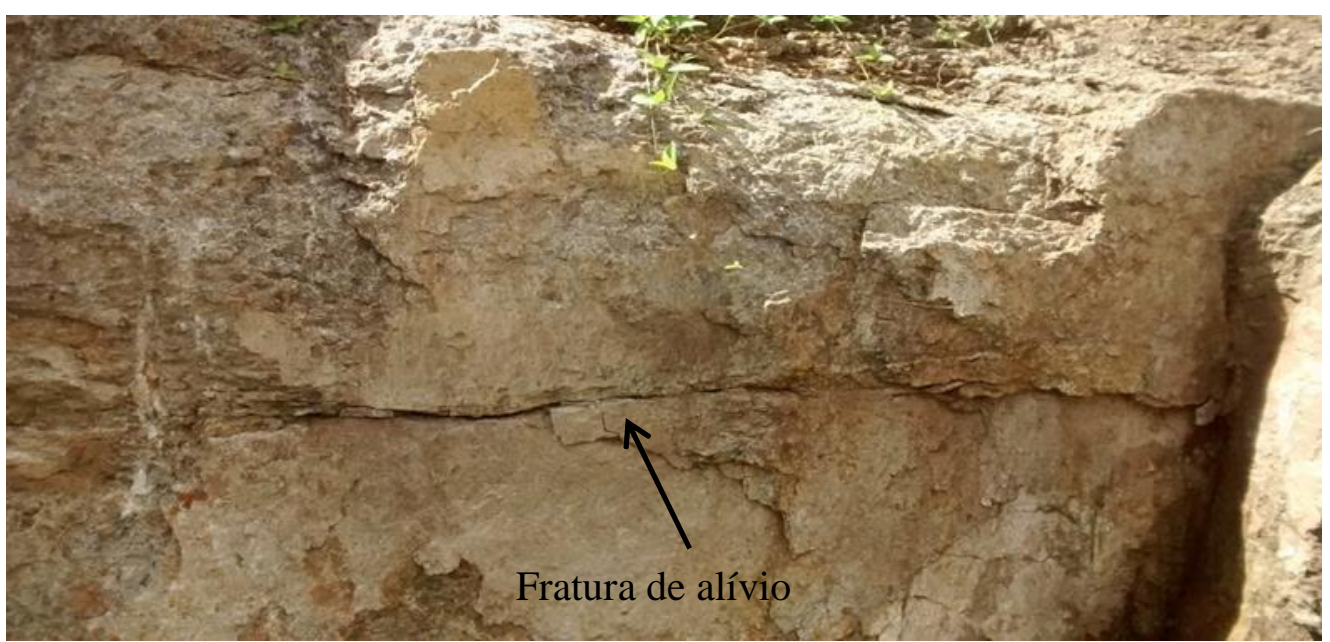

Figura 11. Fratura de alívio em Umari, João Alfredo-PE.

\section{Descrição petrográfica}

A preparação das lâminas e análises petrográficas foram desenvolvidas no Departamento de Geologia da Universidade Federal de Pernambuco, aplicando-se a norma NBR 15845/2010.

O feldspato alcalino é o principal constituinte mineralógico, representado principalmente por grandes cristais de ortoclásio e subordinadamente por microclínio. Exibe geminações Carlsbad e/ou albita+periclina gerando aspecto axadrezado e com presença de pertitas (exsolução), onde a fase sódica dispõe-se em filetes e/ou chamas, e ocorre também como hóspede no plagioclásio de composição albítica (antipertita). Comumente seus cristais exibem zonamento oscilatório. Ocorre predominantemente na forma de grandes cristais ripiformes, subédricos, com dimensões médias de $15 \mathrm{~mm}$ x 12,5 mm, e aspecto turvo devido ao processo de alteração. São frequentemente circundados por grãos menores (auréolas) de cor rosa, branco ou laranja, minerais máficos de cor preta a preta esverdeada e quartzo. Os minerais máficos estão representados pela biotita, piroxênio e anfibólio.
O plagioclásio é representado pela albita e oligoclásio. Ocorrem como hóspedes no feldspato potássico, formando pertitas em filetes e/ou chamas e também como hospedeiros do feldspato potássico, formando antipertitas. Apresenta-se também como grandes cristais ou como constituinte das auréolas. Exibe geminações polissintéticas do tipo albita e periclina, com dimensões médias de 12,5 mm x 10 $\mathrm{mm}$.

Fortes correlações entre $\mathrm{SiO}_{2}$ $\mathrm{Al}_{2} \mathrm{O}_{3}-\mathrm{K}_{2} \mathrm{O}$ refletem a presença de feldspatos potássicos (Kf), como principal mineral silicático destas fácies. Os minerais máficos estão representados pela biotita, piroxênio e anfibólio; titanita e apatita como acessórios; sericita, argilominerais e epidoto, como minerais secundários.

O anfibólio é representado pela hornblenda, que se apresenta com pleocroísmo verde- oliva a verde-claro, dimensões médias de $0,875 \mathrm{~mm}$ x 0,400 $\mathrm{mm}$, ocorrendo como agregados ou em prismas anédricos e subédricos contendo inclusões de minerais opacos, apatita e biotita.

A biotita ocorre geralmente subédrica, cor castanha com tonalidade 
avermelhada, e dimensões médias de 1,6 $\mathrm{mm}$ x 1,0 mm. Associa-se aos anfibólios e piroxênios. Costuma ser produto da reação sub-sólido do anfibólio (hornblenda) Ocorre principalmente como inclusões nos feldspatos. $\mathrm{O}$ piroxênio (clinopiroxênio) é representado pela aegerina- augita. Subédrico, dimensões médias de $1,4 \mathrm{~mm} \times 1,1 \mathrm{~mm}$, tons variando de verde- amarelado a castanho.

A apatita é um dos acessórios mais frequentes, mostrando hábito prismático e acicular, e se apresentando como inclusões nos feldspatos e nos minerais máficos, com dimensão $0,45 \mathrm{~mm}$ x 0,20 $\mathrm{mm}$; enquanto a titanita apresenta-se subédrica, com dimensão média de 0,5 mm,. Associa-se aos anfibólios e aos minerais opacos. Estes últimos são primários e ocorrem dispersos em grãos paralelogrâmicos ou cúbicos, e dimensões médias de $0,10 \mathrm{~mm}$. Provavelmente tratase de cristais de ilmenita e magnetita.

O quartzo mostra-se anédrico com extinção ondulante, disposto em zonas concêntricas nos intercrescimentos, com dimensões de até $2 \mathrm{~mm}$ x $0,75 \mathrm{~mm}$. Os contatos entre os grãos são do tipo plano, quando entre cristais de feldspatos (predominantemente no tipo escuro) e côncavo-convexos, quando entre minerais máficos e félsicos.

A pequena quantidade de microfissuras e de minerais de alteração presentes sugere que a rocha deve apresentar baixo índice de absorção e porosidade, tendo consequentemente boa resistência à flexão e à compressão. Imagens petrográficas são observadas nas Figuras 12,13 e 14

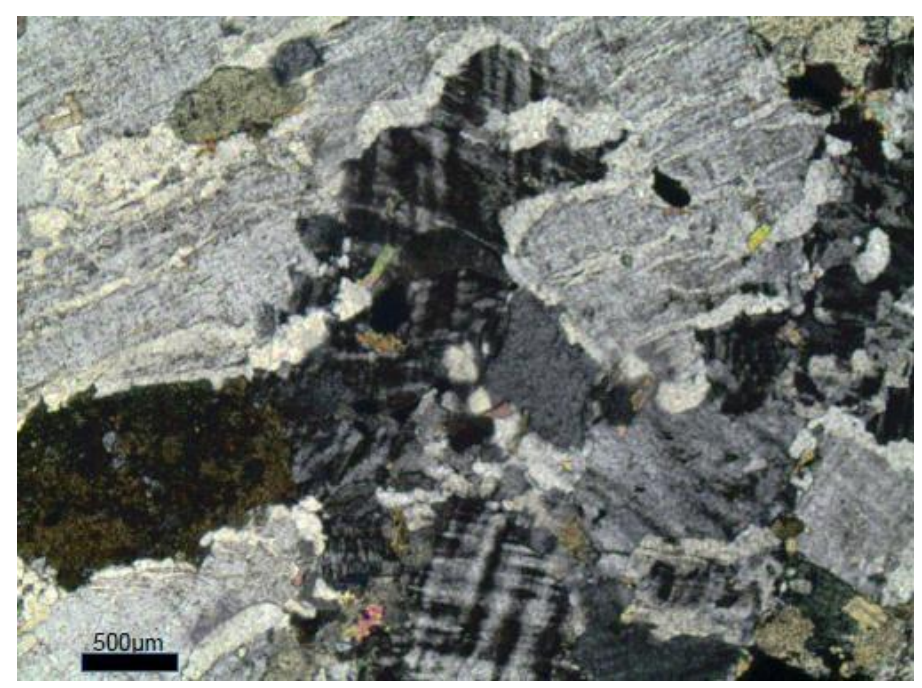

Figura 12. Textura pertítica, interstícios com piroxênio cor verde. Fonte: Departamento de Geologia da Universidade Federal de Pernambuco. 


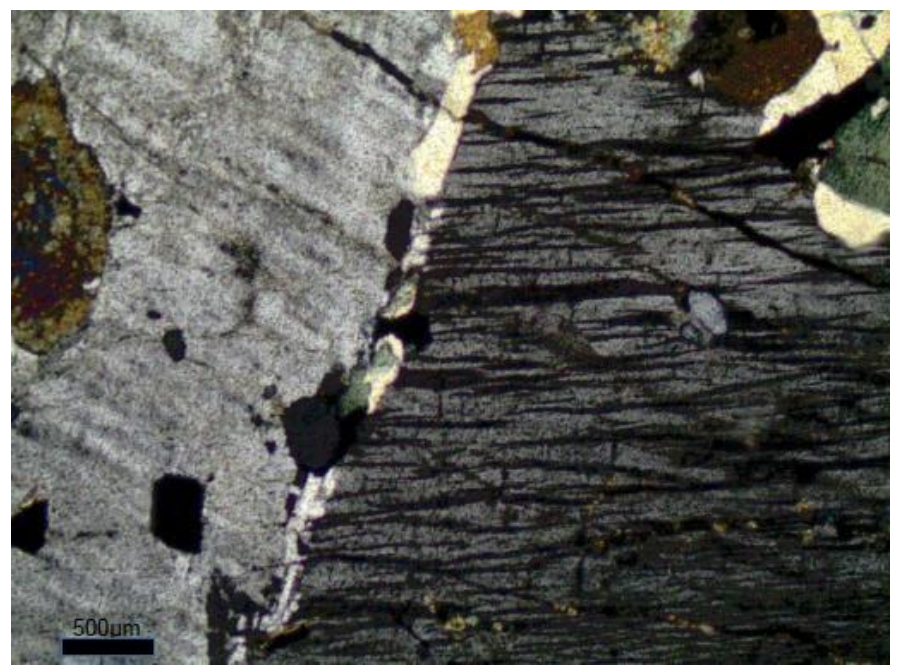

Figura 13. Cristais de quartzo instersticiais (amarelo) em contato com feldspato potássico e plagioclásio. Fonte: Departamento de Geologia da Universidade Federal de Pernambuco.

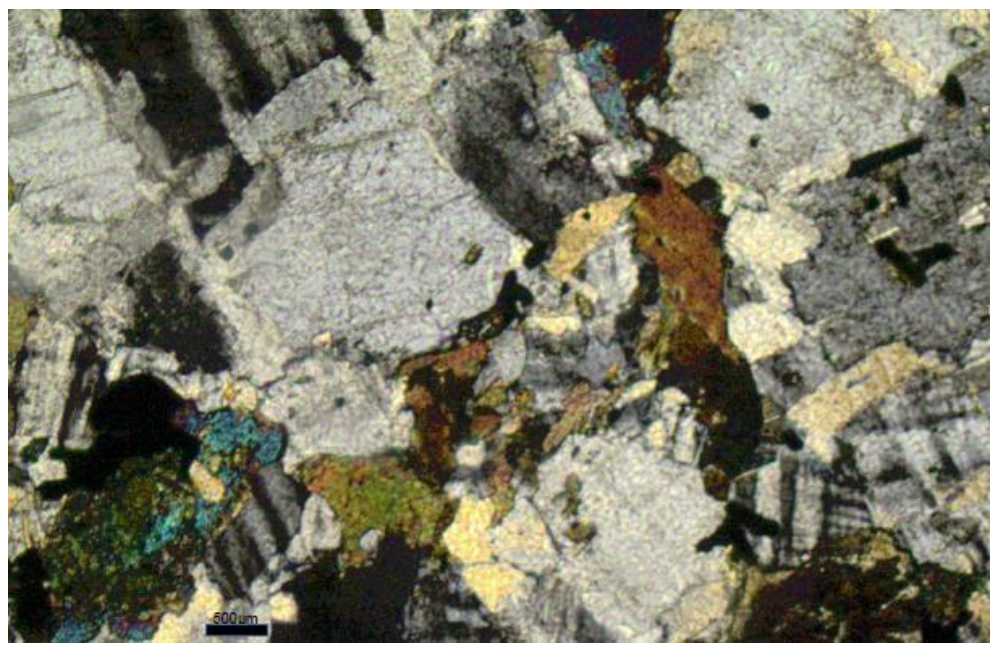

Figura 14. Cristais anedral de olivina cor de interferência azul esverdeada, em contato com plagioclásio e vezes com inclusões de quartzo amarelo. Fonte: Departamento de Geologia da Universidade Federal de Pernambuco.

\section{Índices físicos}

Os ensaios para a determinação dos índices físicos (massa específica aparente, porosidade e absorção aparentes), foram desenvolvidos no Laboratório de Rochas Ornamentais do PPGEMinas da Universidade Federal de Pernambuco, utilizando-se a norma ABNT NBR 15845:2010.

O ensaio de compressão uniaxial, módulo de ruptura (flexão por 3 apoios) e resistência ao impacto de corpo duro seguiram a normativa da ABNT NBR 15845:2010. Já os ensaios para determinação do desgaste abrasivo Amsler, seguiram os procedimentos da norma da ABNT NBR 12042:1992. Esses testes foram realizados no Laboratório de Estruturas do Departamento de Engenharia Civil da UFPE.

A Tabela 2 apresenta um quadro resumo com os valores obtidos. 
Maria Carolina de Albuquerque Feitosa Amador et al.

Tabela 2. Resumo dos ensaios de caracterização tecnológica.

\begin{tabular}{|l|l|l|l|l|l|l|c|}
\hline \multicolumn{1}{|c|}{$\begin{array}{l}\text { Resultado/ } \\
\text { Referências }\end{array}$} & $\begin{array}{l}\text { Abs. de } \\
\text { água } \\
(\boldsymbol{\%})\end{array}$ & $\begin{array}{l}\text { Massa } \\
\mathbf{s e c a} \\
\left(\mathbf{K g} / \mathbf{m}^{\mathbf{3}}\right)\end{array}$ & $\begin{array}{l}\text { Porosidade } \\
(\boldsymbol{\%})\end{array}$ & $\begin{array}{l}\text { Res. } \\
\text { Compr. } \\
(\mathbf{M p a})\end{array}$ & $\begin{array}{l}\text { Res. } \\
\text { Flexão } \\
(\mathbf{M p a})\end{array}$ & $\begin{array}{l}\text { Res. Imp. } \\
(\mathbf{m})\end{array}$ & $\begin{array}{l}\text { Desg. Amsler } \\
(\mathbf{m m} / \mathbf{1 0 0 0 m})\end{array}$ \\
\hline $\begin{array}{l}\text { Marrom } \\
\text { Imperial }\end{array}$ & 0,4 & 2,807 & 0,782 & 93,3 & 8,57 & 0,35 & 0,81 \\
\hline $\begin{array}{l}\text { ABNT } \\
\text { NBR } \\
15845\end{array}$ & $<0,4$ & $>2,55$ & $<1$ & $>100$ & $>10$ & 0,3 & N.E. \\
\hline $\begin{array}{l}\text { ABNT } \\
\text { NBR } \\
12042\end{array}$ & N.E. & N.E. & N.E. & N.E. & N.E. & N.E. & $<1,0$ \\
\hline ASTM C615 & $<0,4$ & $>2,56$ & N.E. & $>131$ & $>10,34$ & N.E & N.E \\
\hline
\end{tabular}

A partir da tabela acima, é possível observar que o resultado obtido no ensaio de densidade (massa seca) nas amostras é acima dos valores estipulados pelas normas brasileira e americana. Valores elevados de densidade podem indicar que a rocha apresenta baixa porosidade e também baixa absorção de água, assim como sugerem que o material possivelmente apresenta boa resistência à compressão. Essa hipótese foi confirmada ao observar o valor de $0,782 \%$ de porosidade e absorção de água dentro do limite aceitável pela norma brasileira, tendo em vista que a americana não apresenta especificação para esta propriedade. Porosidade baixa associada à densidade elevada indica que este material contém poucos vazios em sua massa.

Assim, rochas que apresentem estes índices podem ser usadas sem restrições em áreas internas ou externas, secas ou úmidas. No entanto, por questão de cautela, indica-se a impermeabilização do material para aplicações em ambientes úmidos, uma vez que a absorção de água encontra-se no máximo estabelecido, assim como evitar áreas úmidas como banheiros, cozinhas e áreas externas.
No teste de compressão uniaxial, as amostras são submetidas a uma pressão que provoca o cisalhamento capaz de rompê-las, neste momento alcança-se a resistência à compressão. Vale ressaltar que os valores obtidos são resultados não só da força aos quais os blocos estão submetidos, mas também da interrelação entre aspectos intrínsecos da rocha, entre os quais é possível citar a composição mineralógica, granulometria, as fraturas e microfraturas da rocha. O Marrom Imperial possui resistência à compressão simples abaixo dos limites estabelecido pela norma ASTM C615 e ABNT NBR15845.

O módulo de ruptura por flexão (MPa) é um dos ensaios mais importantes e necessários para revestimento externo de fachadas com rochas ornamentais para dimensionamento de placas a serem utilizadas no revestimento de fachadas com o uso de sistemas de ancoragem metálica para a sua fixação, como visto, o Marrom Imperial apresenta valor de 8,57; abaixo do limite sugerido pela ABNT . Devido a isto, não deve ser aplicada em áreas constantemente solicitadas à tração, como em painéis de edifícios sob a ação dos ventos, entre outras situações. 
A ABNT, através da NBR 12042:1992 estabelece o limite de $\leq 1,0$ $\mathrm{mm}$ para percursos de $1000 \mathrm{~m}$ para que as rochas sejam consideradas de boa qualidade a serem utilizadas em revestimentos de pisos de grande circulação. Apesar do limite ter sido atendido, levando-se em consideração a composição mineralógica e baixa resistência a compressão, desaconselhase o uso em áreas de grande tráfego de transitantes.

Os valores expostos na Tabela 2 quanto a resistência ao impacto de corpo duro, denotam uma rocha com satisfatória resistência ao impacto, capaz de suportar ação mecânica instantânea (golpe ou impacto). Devido ao resultado estar bem próximo ao mínimo recomendado, deve-se ter cuidado aos choques no transporte, estocagem, colocação e restrições a aplicações quanto a piso.
Esta pesquisa buscou conhecer o padrão geoestrutural da jazida de sienito Marrom Imperial, localizada no Sítio Pau Santo, João Alfredo - PE, apontando a orientação da lavra segundo a direção de alívio do campo de tensões atuantes sobre o maciço rochoso, buscando sua melhor produtividade e aumento da recuperação da pedreira, assim como avaliar as características físicomecânicas, petrográficas e mineralógicas da rocha ornamental para uma aplicação adequada.

A análise do fraturamento revelou que a tensão máxima de compressão está na direção é N5E e a tensão mínima de compressão é $95^{\circ} \mathrm{Az}$, conforme observado na figura 15. A interpretação dos diagramas permitiu concluir que a melhor direção para se efetuar o corte da pedreira, de forma a provocar o alívio das tensões, sem fissurar a rocha é SENW.

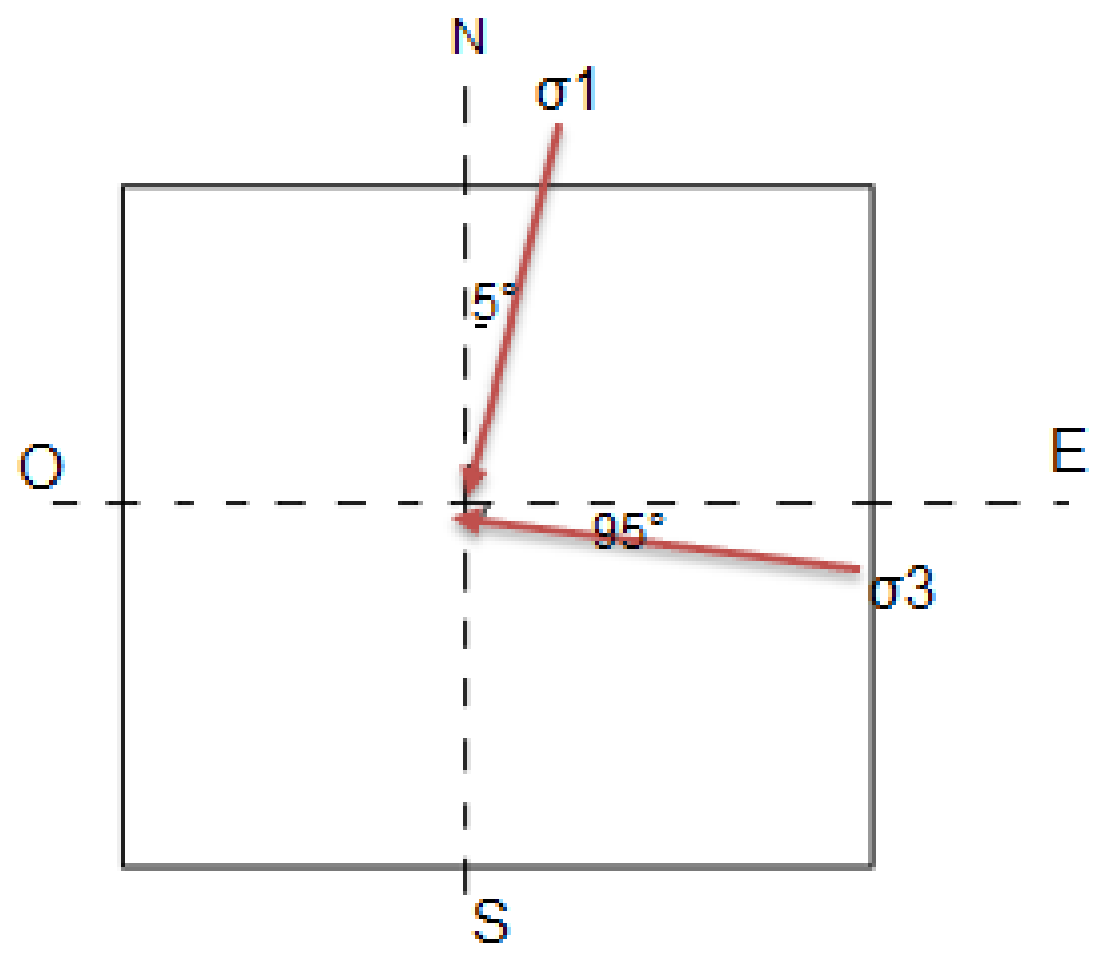

Figura 15. Direção das tensões principais atuantes no maciço estudado: $\sigma 1$ direção de compressão máxima, $\sigma 3$ direção de compressão mínima. 


\section{CONCLUSÕES}

Quanto à caracterização tecnológica pode-se afirmar que os índices físicos (densidade aparente, porosidade e absorção d'água), desgaste Amsler e testes de resistência ao impacto atendem satisfatoriamente aos requisitos da ABNT NBR 15845:2010, e americana ASTM C615:1992. No entanto, o mesmo não pode ser considerado para resistência à compressão simples e de resistência por flexão.

A avaliação dos ensaios do Marrom Imperial possibilitou um melhor conhecimento da inter-relação dos resultados, possibilitando uma melhor aplicação do material objeto de estudo. Comparando-se os resultados obtidos com as normas apresentadas nesse trabalho, pode-se afirmar que a rocha não deve ser utilizada como piso devido à sua absorção de água e baixa resistência a compressão. Da mesma maneira não é aconselhada seu uso como revestimento externo de elevadas fachadas, pela sua baixa resistência a flexão. Assim a melhor aplicação destina-se a áreas internas e secas.

\section{REFERÊNCIAS}

ABNT NBR 12042. Materiais Inorgânicos. Determinação do Desgaste por Abrasão. 1992.

ABNT NBR 15845. Rochas para revestimento. Métodos de Ensaio. ANEXO A (normativo) Análise Petrográfica. 2010.

Rochas para revestimento. Métodos de Ensaio. ANEXO B (normativo) Densidade aparente, porosidade aparente e absorção de água. 2010.

Rochas para revestimento. Métodos de Ensaio. ANEXO E (normativo) Resistência à Compressão Uniaxial. 2010.

2010. Rochas para revestimento. Métodos de Ensaio. ANEXO G (normativo) Módulo de Ruptura (Flexão por carregamento de três pontos). 2010._. Rochas para revestimento. Métodos de Ensaio. ANEXO $\mathrm{H}$ (normativo) Resistência ao Impacto de Corpo Duro..

ASTM C615. Standard Specification for Granite Dimension Stone. 1992.

Frazão, E. B.; Frajallat, J. E. S. 1995. Características Tecnológicas das Principais Rochas Silicáticas Brasileiras Usadas como Pedras de Revestimento. In: CONGRESSO INTERNACIONAL DA PEDRA, 1., Lisboa..

Ladeira, E.A.; Loczy L. 1976. Geologia Estrutural e Indrodução à Geotectônica. São Paulo: Edgard Bluder. 528p.

Mendes, V. C., 2008. Estudo Geoestrutural do Maciço de Granito Vermelho Frevo SertâniaPE. Dissertação de mestrado, Programa de Pós Graduação em Engenharia de Mineral - UFPE.

Ragan, D. M. 2009. Structural Geology: An Introduction to geometrical techniques. New York: Fourth Edition. 602p.

Vidal, F. W. H., Azevedo, H. C. A., Castro, N. F. 2013. Tecnologia de Rochas Ornamentais: Pesquisa, Lavra e Beneficiamento. Rio de Janeiro: CETEM/MCTI. 700p. 